\title{
BMJ Open Māori patients' experiences and perspectives of chronic kidney disease: a New Zealand qualitative interview study
}

\author{
Rachael C Walker, ${ }^{1,2}$ Shayne Walker, ${ }^{3}$ Rachael L Morton, ${ }^{4}$ Allison Tong, ${ }^{1,5}$ \\ Kirsten Howard, ${ }^{1}$ Suetonia C Palmer ${ }^{6}$
}

To cite: Walker RC, Walker S, Morton RL, et al. Māori patients' experiences and perspectives of chronic kidney disease: a New Zealand qualitative interview study. BMJ Open 2017;7: e013829. doi:10.1136/ bmjopen-2016-013829

- Prepublication history and additional material is available. To view please visit the journal (http://dx.doi.org/ 10.1136/bmjopen-2016013829).

Received 11 August 2016 Revised 16 November 2016 Accepted 20 December 2016

CrossMark

For numbered affiliations see end of article.

Correspondence to Rachael C Walker; rachaelwalker14@gmail.com

\section{ABSTRACT}

Objectives: To explore and describe Māori (the indigenous people of New Zealand) patients' experiences and perspectives of chronic kidney disease (CKD), as these are largely unknown for indigenous groups with CKD.

Design: Face-to-face, semistructured interviews with purposive sampling and thematic analysis.

Setting: 3 dialysis centres in New Zealand (NZ), all of which offered all forms of dialysis modalities.

Participants: 13 Māori patients with CKD and who were either nearing the need for dialysis or had started dialysis within the previous 12 months.

Results: The Māori concepts of whakamā (disempowerment and embarrassment) and whakamana (sense of self-esteem and selfdetermination) provided an overarching framework for interpreting the themes identified: disempowered by delayed CKD diagnosis (resentment of late diagnosis; missed opportunities for preventive care; regret and self-blame); confronting the stigma of kidney disease (multigenerational trepidation; shame and embarrassment; fear and denial); developing and sustaining relationships to support treatment decisionmaking (importance of family/whānau; valuing peer support; building clinician-patient trust); and maintaining cultural identity (spiritual connection to land; and upholding inner strength/mana).

Conclusions: Māori patients with CKD experienced marginalisation within the NZ healthcare system due to delayed diagnosis, a focus on individuals rather than family, multigenerational fear of dialysis, and an awareness that clinicians are not aware of cultural considerations and values during decision-making. Prompt diagnosis to facilitate self-management and foster trust between patients and clinicians, involvement of family and peers in dialysis care, and acknowledging patient values could strengthen patient engagement and align decision-making with patient priorities.

\section{BACKGROUND}

Indigenous people worldwide bear a greater burden of disease, disability and death than
Strengths and limitations of this study

- In-depth face-to-face interviewing allowed for a detailed understanding of patients' experiences and values of experiencing kidney disease.

- The feedback from member checking confirmed our interpretation of raw data and grouping of themes and subthemes.

- A limitation of this study is that we did not explore patients' experiences and perspectives of transplantation.

- We did not include or evaluate the considerations of wider determinants of health outcomes such as poverty.

their non-indigenous counterparts. ${ }^{1}$ Māori, the indigenous people of New Zealand (NZ), experience inequities in most health conditions. ${ }^{2}$ Māori, like many other indigenous people, are affected by end-stage kidney disease (ESKD) disproportionately, contributing to persistent and marked inequity in health outcomes. ${ }^{3}$ Despite stabilised rates of dialysis in higher income countries, the incidence of ESKD continues to increase for Māori. Māori have been consistently 3.5 times more likely to start dialysis than NZ Europeans, and have a very low likelihood of receiving best practice treatment including pre-emptive kidney transplantation and home-based dialysis. ${ }^{3-7}$

Previous literature highlights marginalisation for Māori within the NZ health system. $^{8-10}$ Inequities in provision of preventative care, delayed specialist referral and lower life expectancy among indigenous peoples have been extensively quantified and explored using epidemiological methods, but remain incompletely explained by conventional individual and community risk factors for worse health outcomes, including socioeconomic opportunity and comorbidity. ${ }^{11}$ Previous international research has highlighted specific issues for indigenous groups 
in chronic kidney disease (CKD) such as providing culturally competent care, ${ }^{12} 13$ the need for flexible familyfocused care, managing patient fear of mainstream services ${ }^{12}$ and miscommunication; ${ }^{14}$ however, these issues have not been explored among Māori patients with CKD. This study aims to describe Māori patients' beliefs and experiences of CKD which may elucidate additional contextual, social and organisational factors that contribute to the persistent inequities in health outcomes among Māori with CKD.

\section{METHODS}

This substudy reports new data specific to Māori participants describing their experiences and beliefs of CKD collected as part of the larger 'Home First study': a semistructured interview study with adult patients with CKD stage $4-5 \mathrm{D}$ (on dialysis <1 year) and their caregivers recruited from three nephrology centres in NZ. ${ }^{15}$

\section{Participant recruitment and selection}

This analysis specifically focused on interviews conducted with 13 participants from the Home First study, all of whom self-identified as NZ Māori and had received education about treatment modalities (dialysis and kidney transplantation) or who had started dialysis within the previous 12 months. Participants were recruited to the study by nephrologists and nurse specialists working across three nephrology units (two large metropolitan urban units and one small regional unit). The study was explained to participants who received written information and an opportunity to ask any questions before written consent was sought. Each unit has an established predialysis programme and offers all dialysis modalities. The 3 units were chosen as they offered a mixture of ethnicities representative of the NZ dialysis population. None of the Māori participants approached declined to participate in the study. The study is reported according to the Consolidated Criteria for Reporting Qualitative Research (COREQ) ${ }^{16}$ (see online supplementary file 1 ).

\section{Data collection}

A semistructured face-to-face interview was conducted with each participant in the patient's choice of either their home or a clinic room at the hospital between July 2014 and January 2015 by one author, who is a female nurse practitioner in renal medicine, experienced in qualitative research (RCW); some participants were known to the interviewer. The interview guide included questions about cultural issues that influence decisions about dialysis choice or place of dialysis and how cultural and spiritual needs can be better met. This guide was developed after a review of the literature and discussion among the research team which consisted of renal clinicians and social scientists experienced in qualitative research and Māori cultural advisors (see online supplementary file 2). All interviews were digitally recorded and transcribed with the participants' consent, and the interview length ranged between 35 and 120 min each. Interviews were conducted until data saturation was achieved.

\section{Data analysis}

All transcripts were entered into specialised software (HyperRESEARCH; V.3.7.2 ResearchWare) to manage and analyse data. Field notes were also written during interviews. Using adapted grounded theory and thematic analysis, RCW, SW (who identifies as a Māori and is an experienced Māori policy writer and cultural advisor) and SCP (nephrologist) independently coded the transcripts provided by the 13 participants line by line, and inductively identified concepts. Similar concepts were then grouped together into themes. The conceptual framework and data interpretation were independently reviewed by three authors (RCW, SW and SCP) to ensure that the themes reflected the full scope of the data and were consistent with the Māori world (Te Ao Māori) view. The coding schema was refined through a series of discussions among the investigator team.

Once thematic analysis was complete, we convened a discussion group with four Māori patients including three who had participated in the qualitative interviews. We discussed the preliminary themes to ascertain whether they had been interpreted to reflect the range and depth of perspectives of Māori patients. We also offered an opportunity for patients to discuss and respond to the identified themes (ie, member checking). Participants from the discussion group validated our interpretation of the findings, subthemes and themes.

\section{RESULTS}

Of the 13 participants (table 1), 7 (54\%) patients were not yet on dialysis (but had received education about dialysis), 3 (23\%) were treated with home dialysis (either haemodialysis or peritoneal dialysis) and 3 (23\%) were treated with in-centre haemodialysis. The participants were aged from 22 to 72 years (mean age 59 years). Ten participants $(77 \%)$ had ESKD caused by diabetes. Participant characteristics are presented in table 1.

We identified the Māori concepts of whakamā (disempowerment and embarrassment) and whakamana (enhanced self-esteem and self-determination) provided an overarching framework for interpreting the themes identified: disempowered by delayed CKD diagnosis, confronting the stigma of dialysis, developing and sustaining relationships to support treatment, and maintaining cultural identity. Illustrative participant quotes are provided in table 2. Conceptual links between themes are presented in figure 1 .

\section{Disempowered by delayed CKD diagnosis Resentment of late diagnosis}

Some participants experienced delayed diagnosis of CKD despite the patients regularly attending their general practitioner for clinical assessment and diabetes 
Table 1 Patient characteristics

\begin{tabular}{|c|c|}
\hline Characteristics & Patients, N (\%) \\
\hline \multicolumn{2}{|l|}{ Age category (years) } \\
\hline $20-40$ & $1(8)$ \\
\hline $41-60$ & $3(23)$ \\
\hline $61-80$ & $9(69)$ \\
\hline \multicolumn{2}{|l|}{ Dialysis modality } \\
\hline Predialysis & $5(38)$ \\
\hline Peritoneal dialysis & $4(31)$ \\
\hline Home haemodialysis & $1(8)$ \\
\hline In-centre (facility) dialysis & $3(23)$ \\
\hline \multicolumn{2}{|l|}{ Marital status } \\
\hline Married/de facto & $7(54)$ \\
\hline Divorced/separated & 0 \\
\hline Single & $3(23)$ \\
\hline Widowed & $3(23)$ \\
\hline \multicolumn{2}{|l|}{ Highest level education } \\
\hline Some primary school & $4(31)$ \\
\hline Some secondary & $3(23)$ \\
\hline Completed certificate or diploma & $3(23)$ \\
\hline Completed degree/higher & $3(23)$ \\
\hline \multicolumn{2}{|l|}{ Employment status } \\
\hline Full-time & $4(31)$ \\
\hline Part-time/casual & $2(15)$ \\
\hline Not employed & $2(15)$ \\
\hline Social Welfare Beneficiary & $3(23)$ \\
\hline Retired & $2(15)$ \\
\hline \multicolumn{2}{|c|}{ Estimated gross annual household income } \\
\hline NZ\$10-30000 & $2(15)$ \\
\hline$N Z \$ 31-50000$ & $7(54)$ \\
\hline NZ\$51-70 000 & $4(31)$ \\
\hline NZ\$71-100 000 & 0 \\
\hline$>\mathrm{NZ} \$ 101000$ & 0 \\
\hline \multicolumn{2}{|c|}{ Time to dialysis unit (travelled one way) (minutes) } \\
\hline $0-20$ & $5(65)$ \\
\hline $21-40$ & $4(31)$ \\
\hline $41-120$ & 0 \\
\hline$>120$ & $4(31)$ \\
\hline
\end{tabular}

checks. Patients felt frustrated and let down that although they often voiced specific concerns these were often ignored. Reflecting on previous care, participants were angry that their doctor had apparently failed to pay attention to their kidney function during their regular diabetes clinical checks, or neglected to communicate the risk or diagnosis of this to the patient.

\section{Missed opportunities for preventative care}

Many participants expressed disappointment that the system had let them down, as they were unaware of the preventative measures they could have taken to protect their kidney function and delay dialysis. Participants described how health professionals implied that there was an expectation that they already should have an awareness of their kidney problems and how to take care of themselves.
Regret and self-blame

Many participants, particularly those with diabetes, expressed regret that they could have avoided or delayed dialysis. Despite many acknowledging they had not known enough to make significant changes earlier, many blamed themselves for not proactively asking about treatment or lifestyle changes, or trying to understand more about their condition to help them selfmanage their care, internalising a sense of inadequacy. These experiences often led to loss of confidence in their own ability to care for themselves when considering home dialysis and disengagement with predialysis education and dialysis decision-making.

\section{Confronting the stigma of dialysis}

\section{Multigenerational trepidation}

Stories of sickness and death on dialysis relayed to them by their family members instigated fears and anxiety of what life on dialysis would entail. Some patients had experienced first-hand close or extended family having dialysis, and associated dialysis closely with death. Although participants understood that many of these experiences were personal, and may not be the same for them, the bad memories or tales of dialysis often influenced their own dialysis choice, particularly increasing their fear of home dialysis modalities.

\section{Shame and embarrassment}

Participants felt embarrassed and ashamed of having kidney disease and the community stigma associated with kidney disease as it was perceived as self-induced. Many participants, often men, associated sickness with weakness and inferiority from their peers. For men who had been always physically active and perceived as strong, the need to be dependent on others and a machine made them feel ashamed and often led to withdrawing from family and not participating in dialysis education and preparation.

\section{Fear and denial}

Fear of having to live with dialysis created uncertainty of the future for patients and often led to denial of their kidney disease. Many acknowledged that although they were conscious that they were in denial, they did not have the strategies or support to reach acceptance. For this reason, participants chose to withdraw and were reluctant to participate in dialysis education programmes, support groups or discuss their kidney disease with their families. Many described a lack of safe and relevant support networks to 'open-up and face their fears' during the process of preparing for dialysis.

\section{Developing and sustaining relationships to support treatment decision-making \\ Importance of family/whānau}

Participants valued the importance of including family in their early care and decision-making. When not offered the opportunity to involve their family in the decision-making process about dialysis, this led to 
Table 2 Participants' illustrative quotes

\begin{tabular}{|c|c|}
\hline Themes & Participant quotes \\
\hline \multicolumn{2}{|c|}{ Disempowered by delayed CKD diagnosis } \\
\hline Resentment of late diagnosis & $\begin{array}{l}\text { "I kept going to him [general practitioner], saying there's something else wrong, it's } \\
\text { just not just my sugar diabetes that's wrong, there's something else" (Pre-dialysis 4). }\end{array}$ \\
\hline & $\begin{array}{l}\text { "why hasn't someone in the medical profession told me [about kidney disease], I'm } \\
\text { not just coming in to have the wipers fixed or the door handle fixed, I'm coming in for } \\
\text { you to give me a going over from top to bottom" (Pre-dialysis 2). }\end{array}$ \\
\hline
\end{tabular}

Missed opportunities for preventative care

Regret and self-blame
"I just didn't understand it, and so I didn't make the changes to my diabetes it just didn't sound like something I needed to listen to, like it was a problem" (Peritoneal Dialysis 4).

"It was really vague, your creatinine or something is really high, or you've got protein in your urine or something or rather, but no explanation of what that meant, but like I should automatically know what it meant and know what that meant for me and what to do about it" (Peritoneal Dialysis 3).

"I hated going to the doctor, being told off, but now when I think back, I was dumb, I didn't go, didn't take my insulin, didn't take my pills, drunk too much, smoked, you know everything you shouldn't do" (Peritoneal Dialysis 4).

"I'm embarrassed to say, it's actually a lot of education to learn it [home hemodialysis], I have to learn how to do the machine, and they said its hard, and it takes a long time, I guess I'm just not sure if I can learn it, and I'm not that good, and I felt a lot of pressure to learn at their level and I didn't really understand, but I don't want to tell them or they'll think I'm dumb" (In-centre Haemodialysis 2).

\section{Confronting the stigma of kidney disease}

Multigenerational trepidation

Shame and embarrassment

Fear and denial
"I knew some old people in town who had been on dialysis and they always looked terrible and died, I thought it was the dialysis that made them look terrible, and made them die, that's what lots of people think" (Peritoneal Dialysis 2).

"My nan used to be on the bag [peritoneal dialysis], she told me not to go on the bag and do haemo [dialysis], she was sick when she was on the bags, and so was my nanas cousin. I haven't met anyone who did good on PD [peritoneal dialysis]" (In-centre haemodialysis 2).

"The D word, dialysis and death" (Peritoneal Dialysis 1).

"I didn't tell anybody, I think that's the problem with half of us Māori, not wanting to tell, I think there's this thing, that if you're sick, you're like, embarrassed of it. You're not tough, you don't want people to feel sorry for you, so we don't tell. I couldn't even deal with what was hitting me in the face [dialysis]. There's a thing about kidneys, you know, dialysis, a stigma thing about it” (Peritoneal dialysis 2).

"I didn't want to catch the bus, then everyone knows you're on the bus and everyone knows you're on dialysis, and this is a little town you know, I don't want everyone to know" (Peritoneal dialysis 2).

"I had to put it to the back of my head, not think about it" (Peritoneal dialysis 1).

"It was a big shock, and I did the normal Māori thing, I pretended it wasn't happening. Didn't listen. Tried to be tough" (Peritoneal dialysis 2).

"For people like me, especially Māori men, we're not used to talking about our health and especially being sick or admitting we're sick, it's like you lose some mana [standing] if you are sick, so you just don't deal with it and you don't tell anyone, so you just put your head in the sand a little bit deeper" (Home haemodialysis 1). 
Table 2 Continued

Themes Participant quotes

Developing and sustaining relationships to support treatment decision-making

Importance of family/whānau

"It's really hard to explain sometimes that family are first, that I am not an individual, that I am part of a unit, that then no decision is just mine, but it's also really hard to explain to my whanau what is happening with my kidneys when I don't really know it so well myself" (Facility dialysis 2 ).

"We had a meeting with my nana and my mum, one of the nurses came and talked and that was easier than me talking by myself and trying to answer questions when I didn't know what the right answer was" (Facility dialysis 1).

"If you've got the support of your family and your loved ones, everything is going to be ok" (Home haemodialysis 1).

Valuing peer support

Building mutual clinician-patient trust

\section{Maintaining cultural identity}

Spiritual connection to land

Upholding inner strength/mana
"They walk you through it. I learnt a lot in those sessions. Because it's from your own culture I guess. You just can see the reality there. I learnt a lot from those classes, more than talking to a doctor" (Facility dialysis 3 ).

“Knowing first hand” (Pre-dialysis 1).

"If they understood more about you they'd do things better and you'd do things better and then I'd trust them if they told me I could go home and do home, you know, but they don't know me and I'm not going to tell them if I don't think they don't care" (Facility dialysis 2).

"I guess a lot of that was trusting, and then feeling comfortable about what [name] were telling me, I needed to hear it from someone I trusted" (Peritoneal dialysis 2).

"If I did have to move into town, then I wouldn't be with my family and they couldn't help me and I couldn't help them with the kids and then what would they do, that wouldn't work, so that's why this stomach one [peritoneal dialysis] will be better at home" (Pre-dialysis 1).

"My involvement with the community at a lower level, I don't want to lose, so basically in terms of having a dialysis machine at my fingertips at home I still want to know I can do all of those things without any pressure on any of those things, cause I am nothing without those things" (Pre-dialysis 4).

"Going to hui [meetings] and going to the marae [meeting house], I guess in a way, that was a lot of the thing why I wanted to do home [dialysis] too. I can work around it. I don't have to miss it" (Home haemodialysis 1 ).

"Cultural too, is the male working thing, the identity of working and being a working man, and the stigma of being sick and on dialysis and not being the tough guy" (Pre-dialysis 3).

CKD, chronic kidney disease.

disconnection within the family and isolation of the patient. In contrast, for patients whose families had been actively involved in case and decision-making, there appeared to be better understanding and support.

\section{Valuing peer support}

Participants drew strength from the experience and support of other Māori patients during their preparations for dialysis treatment. For some participants who felt isolated and that no one would understand the emotions they were dealing with, meeting someone similar whom they could relate to allowed them a sense of belonging. Spending time with peers who had successfully established themselves on dialysis treatment reassured and emboldened patients and helped to allay their specific anxieties about dialysis.

\section{Building mutual clinician-patient trust}

Participants emphasised the importance of developing and sustaining a trusting and therapeutic relationship 


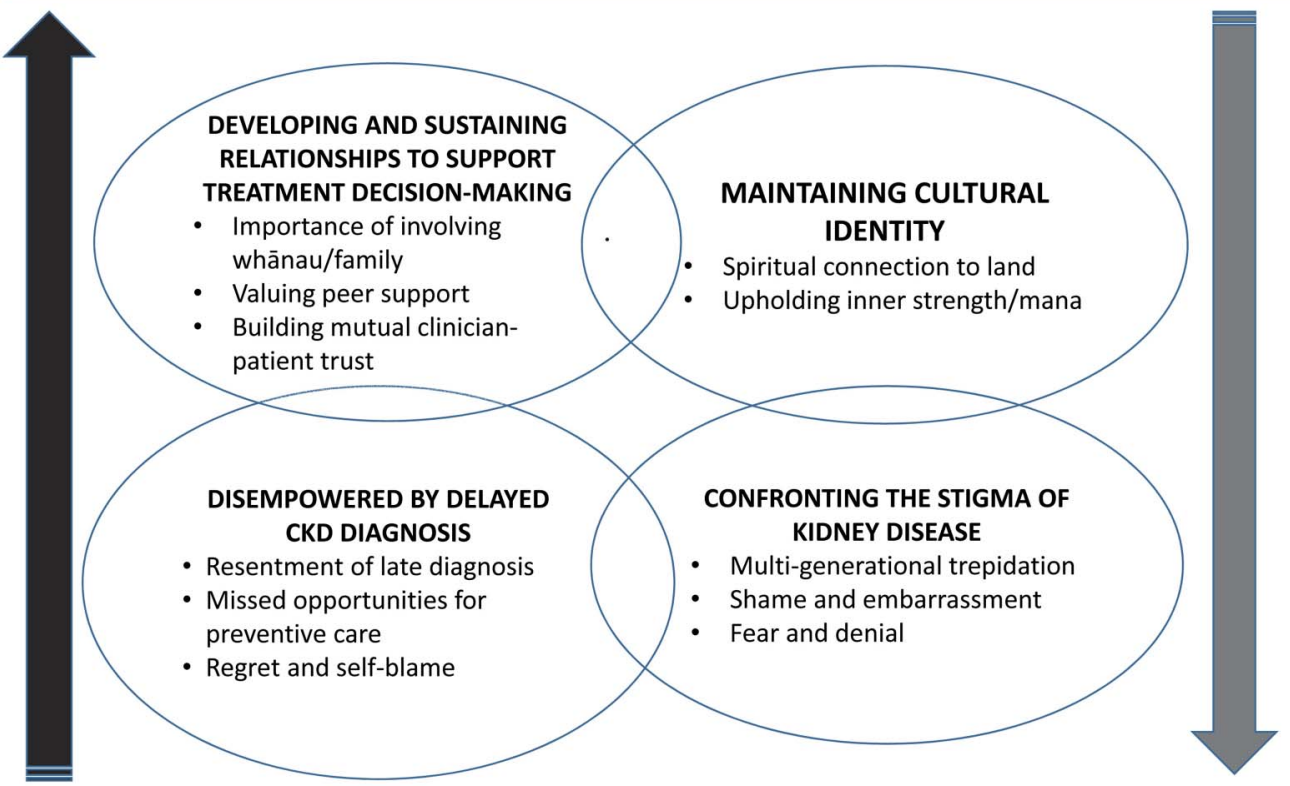

Whakamā - Disempowerment and embarrassment

Figure 1 Thematic schema of Māori patients' experiences and perspectives of chronic kidney disease (CKD). Delayed initial CKD diagnosis and missed opportunities for preventive care and loss of trust and disengagement with health services influenced all other aspects of CKD care for Māori patients and led to embarrassment and disengagement of kidney disease and dialysis (Whakamā). Poor communication led to difficulty in patients translating clinical information to enable self-management, and feeling inadequate during clinical encounters. Multigenerational and community experiences of kidney disease invoked fear, which isolated patients from peer and family support accentuated by an individual-based approach to decision-making and education. Having trusting and reciprocated relationships with clinicians was integral to engaging fully with dialysis preparation, enabled self-care, and enhanced inclusion and engagement in patient decision-making. Feeling listened to and being confident to seek support within and outside of their families enabled patients to choose treatments that sustained cultural identity, standing and roles within the community.

with their clinicians. Clinicians were considered more trustworthy when they knew and discussed what was valued and important to the patient. This aspect of care was seen as a crucial stage of maintaining engagement and active participation with clinical services. Participants who believed that their clinician did not understand them, or their values, expressed doubt about their clinicians' recommendations, and were more hesitant to consider home dialysis.

Distrust of health professionals was often based on previous negative encounters with the health system. In contrast, other participants told of positive experiences with clinicians who actively tried to engage them and enabled participants to develop trust, allowing the participant to regain power and confidence in their decision-making.

\section{Maintaining cultural identity \\ Spiritual connection to land}

For many participants, a marker of quality care was their clinician's acknowledgement and appreciation of the importance of spiritual connections to their land and people. The importance of these connections was particularly spoken about by participants who lived in rural locations, who had contemplated having to relocate for dialysis. Some rural participants limited the range of dialysis options they considered to avoid extended relocation to the city to establish their dialysis care. This often meant that these patients chose a home dialysis option, and predominantly chose peritoneal dialysis, as this had the shortest training time and enabled them to stay on their land.

\section{Upholding inner strength/mana}

When considering choice of dialysis treatment, many spoke of making decisions to enable them to continue in their roles within the family and community, as this was seen as an important aspect of their personal and cultural identity. It was important to participants that clinicians recognised the significance of these roles. Many participants preferred a treatment that would enable continued employment as this was a highly valued part of their identity; for some, this meant they retained their 'mana' inner strength and were still seen as a provider for their family.

\section{DISCUSSION}

In this analysis of Māori patients' beliefs and experiences of CKD, Māori experienced delayed initial CKD 
diagnosis and missed opportunities for preventive care and loss of trust and disengagement with health services. Patients reported that poor communication led to difficulty in patients translating clinical information to enable self-management, and feeling inadequate during clinical encounters. Multigenerational and community stigma and experiences of kidney disease invoked fear and shame, which isolated patients from peer and family support accentuated by an individual-based approach to decision-making and education. Having trusting and reciprocated relationships with clinicians was integral to engaging fully with dialysis preparation, enabled self-care and enhanced participatory decision-making. Feeling listened to and being confident to seek support within and outside of their families enabled patients to choose treatments that sustained cultural identity.

The findings of our study suggest potential actions to improve kidney care for Māori which may also be relevant for other indigenous peoples. The patient experiences in this study are concordant with the perspectives of Aboriginal and Torres Strait Islander patients treated with haemodialysis on ways to improve dialysis care including: the importance of family and relationships within healthcare models and service delivery; the need for service provision aligned with cultural preferences; and fear of healthcare processes generated by intergenerational dialysis experiences. ${ }^{12}$ These findings are also consistent with evidence that delayed initial CKD diagnosis is a potential cause of inequity in healthcare experiences and outcomes for Māori ${ }^{17} 18$ and may account for later presentations to renal services among indigenous groups, preventing adequate preparation for home dialysis, permanent vascular access and preemptive kidney transplantation. ${ }^{19-21}$

The significance of developing and sustaining trusting relationships among clinicians, family and the community has also been identified as central to improving health gains for Māori ${ }^{2} 102223$ and other indigenous groups. ${ }^{12}$ Previous literature has identified poor communication between indigenous patients and clinicians ${ }^{11-14}$ as a barrier to Māori accessing quality and effective healthcare and our study supports this and may explain the number of Māori developing ESKD from diabetes. In a previous study reporting Māori patient experiences of heart disease in NZ, patients considered that poor communication arose both from a lack of practitioner competency together with discrimination against Māori during clinical care.$^{10}$ On the basis of our data, Māori recipients of CKD care in NZ do not consider that existing healthcare services are meeting their needs for adequate communication and engagement, with direct negative implications for their disease trajectory and dialysis preparation. Inclusion of Māori health frameworks within professional development to support health practitioners to translate principles of cultural competency into standard clinical practice ${ }^{2425}$ may help to address ineffective communication with Māori patients, although wider considerations of addressing clinician assumptions, understanding power imbalances between clinicians and patients, and exploring institutional structures that sustain ineffective practices are also likely to be required.

A central finding in this study is the failure of clinicians to disclose an initial diagnosis of CKD to the patient and act on this diagnosis despite regular patient attendance in the primary care setting and regular assessment of glycaemic control and kidney function. These findings are coherent with lower specialist referral rates of Māori than non-Māori by general practice ${ }^{26}$ and are particularly important given the high rates of diabetes in Māori. Delayed referral is generally attributed to patient rather than practitioner behaviour, ${ }^{11} 27$ and requires a wider understanding of this issue and their impact on kidney disease and transplantation in indigenous groups. ${ }^{28} 29$

The use of patient design thinking and journey mapping ${ }^{30} 31$ might aid in better alignment of health services and policies to patient priorities. Potential areas for development and evaluation include enhancing peer support and health literacy, developing Māori group education, ${ }^{10}$ strengthening cultural competencies for clinicians, strengthening family-focused care and education, and co-creating Māori-specific care pathways with patients. Programmes and care pathways designed and supported by Māori may also help to address distrust and increase engagement with health systems.

A strength of our study was the addition of member checking to validate the findings and interpretation of qualitative interviews. The feedback from member checking confirmed our interpretation of raw data and grouping of themes and subthemes. Our study does have limitations that should be considered when interpreting the findings. First, we did not include or evaluate in our study the consideration of the wider social determinants of health outcomes such as poverty, social and educational opportunity. ${ }^{32-34}$ Second, the interviewer (RCW) is non-Māori and therefore may have overlooked cultural nuances; however, we minimised this by ensuring involvement and guidance by Māori health experts and advisors from development of the research questions through to interpretation and coding of findings. Facilitating the group discussion to explore interpretation of findings (member checking) also ensured that we had interpreted the data correctly and our themes were appropriate. Third, the interviewer was known to participants from one centre and this relationship may have resulted in selfcensoring answers, although when compared with participants from other centres, similar themes were identified. Finally, we did not explicitly explore patient experiences of preparing for and accessing kidney transplantation. Given that kidney transplantation is less common in indigenous people $\mathrm{e}^{35} 36$ and best practice care for ESKD, this is a vital aspect worthy of exploration to improve health outcomes for Māori and is recommended for future research. Further research may also explore Māori patients' research priorities and determine in more detail Maori experiences of institutional racism in health. 
In conclusion, Māori patients with CKD experienced marginalisation within the NZ healthcare system due to delayed diagnosis, a focus on individuals rather than family/whānau within health processes, multigenerational negative experiences of dialysis, and diminished awareness of patient values during decision-making. Prompt diagnosis to facilitate self-management and foster trust between patients and clinicians, involvement of family and peers in dialysis care, and acknowledging patient values could strengthen patient engagement, facilitate treatment planning and self-management, and align decision-making with patient priorities.

\section{Author affiliations}

${ }^{1}$ Sydney School of Public Health, University of Sydney, Sydney, New South Wales, Australia

${ }^{2}$ Hawke's Bay District Health Board, Hawke's Bay, Hastings, New Zealand

${ }^{3}$ Maungaharuru-Tangitū Trust, Napier, New Zealand

${ }^{4}$ NHMRC Clinical Trials Centre, Sydney Medical School, University of Sydney, Camperdown, New South Wales, Australia

${ }^{5}$ Centre for Kidney Research, The Children's Hospital at Westmead, Westmead, New South Wales, Australia

${ }^{6}$ Department of Medicine, University of Otago, Christchurch, New Zealand

Acknowledgements The authors would like to thank all patients who volunteered their time to participate in this study.

Contributors RCW designed the study, carried out the patient interviews, coded data, participated in thematic analysis and drafted the manuscript. SCP and SW also independently coded data. RLM, KH and AT assisted in the design of the study, participated in the thematic analysis and performed critical review of the first and subsequent manuscript drafts. SW participated in thematic analysis and performed critical review of the first and subsequent drafts.

Funding This work was supported by the Baxter Clinical Evidence Council research programme, New Zealand Lotteries Health Research Grant and Kidney Health New Zealand. RCW is supported by a University of Sydney APA Scholarship, RLM is supported by an Australian National Health and Medical Research Council Early Career Researcher Fellowship (ID1054216). SCP is supported by a Rutherford Discovery Fellowship from the Royal Society of New Zealand. AT is supported by a National Health and Medical Research Council Fellowship (ID1037162).

Competing interests None declared.

Patient consent Obtained.

Ethics approval The Counties Manukau (Ref: 1771), Hawke's Bay (Ref: 14/06/160) and Capital Coast (Ref: CCDHB13/07/14) Research Ethics Committees approved the study.

Provenance and peer review Not commissioned; externally peer reviewed.

Data sharing statement No additional data are available.

Open Access This is an Open Access article distributed in accordance with the Creative Commons Attribution Non Commercial (CC BY-NC 4.0) license, which permits others to distribute, remix, adapt, build upon this work noncommercially, and license their derivative works on different terms, provided the original work is properly cited and the use is non-commercial. See: http:// creativecommons.org/licenses/by-nc/4.0/

\section{REFERENCES}

1. Gracey M, King M. Indigenous health part 1: determinants and disease patterns. Lancet 2009;374:65-75.

2. Robson B, Harris R. Hauora: Maori standards of health IV: a study of the years 2000-2005. Wellington, New Zealand: Te Ropu Rangahau Hauora a Eru Pomare, 2007.

3. ANZDATA Registry.37th Report. Preliminary Report. 2014: summary of dialysis and transplant in Australia and New Zealand. Adelaide,
Australia: Australia and New Zealand Dialysis and Trasnplant Registry, 2015. http://www.anzdata.org.au

4. Marshall MR, Hawley CM, Kerr PG, et al. Home hemodialysis and mortality risk in Australian and New Zealand populations. $A m$ $J$ Kidney Dis 2011;58:782-93.

5. Walker RC, Hanson CS, Palmer SC, et al. Patient and caregiver perspectives on home hemodialysis: a systematic review. $A m$ J Kidney Dis 2015;65:451-63.

6. Wyld M, Morton RL, Hayen A, et al. A systematic review and meta-analysis of utility-based quality of life in chronic kidney disease treatments. PLoS Med 2012;9:e1001307.

7. Tong A, Lesmana B, Johnson DW, et al. The perspectives of adults living with peritoneal dialysis: thematic synthesis of qualitative studies. Am J Kidney Dis 2013;61:873-88.

8. Wilson D, Barton P. Indigenous hospital experiences: a New Zealand case study. J Clin Nurs 2012;21:2316-26.

9. Elers P. Māori health: issues relating to health care services. Te Kaharoa 2014;7:P 163-172.

10. Kerr S, Penney L, Moewaka Barnes H, et al. Kaupapa Maori action research to improve heart disease services in Aotearoa, New Zealand. Ethn Health 2010;15:15-31.

11. Reid P, Robson B, Jones CP. Disparities in health: common myths and uncommon truths. Pac Health Dialog 2000;7:38-47.

12. Rix EF, Barclay L, Stirling J, et al. The perspectives of Aboriginal patients and their health care providers on improving the quality of hemodialysis services: a qualitative study. Hemodial Int 2015;19:80-9.

13. Rix EF, Barclay L, Wilson S, et al. Service providers' perspectives, attitudes and beliefs on health services delivery for Aboriginal people receiving haemodialysis in rural Australia: a qualitative study. BMJ Open 2013;3:e003581.

14. Cass A, Lowell A, Christie M, et al. Sharing the true stories: improving communication between Aboriginal patients and healthcare workers. Med J Aust 2002;176:466-70.

15. Walker RC, Morton RL, Tong A, et al. Patient and caregive preferences for home dialysis-the Home First study: a protocol for qualitative interviews and discrete choice experiments. BMJ Open 2015:5:e007405.

16. Tong A, Sainsbury P, Craig J. Consolidated Criteria for Reporting Qualitative Research (COREQ): a 32-item checklist for interviews and focus groups. Int J Qual Health Care 2007;19:349-57.

17. Curtis $\mathrm{E}$, Wright $\mathrm{C}$, Wall M. The epidemiology of breast cancer in Maori women in Aotearoa New Zealand: implications for screening and treatment. N Z Med J 2005;118:U1297.

18. Harwood M, Aldington S, Beasley R. Lung cancer in Maori: a neglected priority. N Z Med J 2005;118:U1410.

19. Anderson K, Cunningham J, Devitt J, et al. "Looking back to my family": indigenous Australian patients' experience of hemodialysis. BMC Nephrol 2012;13:114

20. Foote C, Clayton PA, Johnson DW, et al. Impact of estimated GFR reporting on late referral rates and practice patterns for end-stage kidney disease patients: a multilevel logistic regression analysis using the Australia and New Zealand Dialysis and Transplant Registry (ANZDATA). Am J Kidney Dis 2014;64:359-66.

21. McKercher C, Chan HW, Clayton PA, et al. Dialysis outcomes of elderly Indigenous and non-Indigenous Australians. Nephrology 2014;19:610-16.

22. Sheridan NF, Kenealy TW, Kidd JD, et al. Patients' engagement in primary care: powerlessness and compounding jeopardy. A qualitative study. Health Expect 2015;18:32-43.

23. Jansen $\mathrm{P}$, Smith $\mathrm{K}$. Maori experiences of primary health care: breaking down the barriers. N Z Fam Physician 2006;33:298-300.

24. Jones R, Pitama S, Huria T, et al. Medical education to improve Maori health. N Z Med J 2010;123:113-22.

25. Pitama S, Robertson $\mathrm{P}$, Cram F, et al. Meihana model: a clinical assessment framework. N Z J Psychol 2007;36:118.

26. Crengle $S$, Lay-Yee R, Davis $P$, et al. A comparison of Maori and non-Maori patient visits to doctors: the National Primary Medical Care Survey (NatMedCa) 2001/02. Report 6. Wellington: Ministry of Health, 2005.

27. Anderson K, Devitt J, Cunningham J, et al. If you can't comply with dialysis, how do you expect me to trust you with transplantation? Australian nephrologists' views on indigenous Australians' 'non-compliance' and their suitability for kidney transplantation. Int J Equity Health 2012;11:21.

28. Lawton P, Cunningham J, Zhao Y, Jose M, eds. They don't do well, do they? Survival of propensity matched Indigenous transplant \& dialysis patients. 51st Annual Scientific Meeting of the Australian and New Zealand Society of Nephrology, 2015. 
29. Khanal N, Clayton P, McDonald S, Jose MD, Differences in access to kidney transplantation for Indigenous Australians, World Congress of Nephrology 2015, 13-17 March, 2015, Cape Town, South Africa (2015).

30. Tsianakas V, Robert G, Maben J, et al. Implementing patient-centred cancer care: using experience-based co-design to improve patient experience in breast and lung cancer services. Support Care Cancer 2012;20:2639-47.

31. Bate P, Robert G. Experience-based design: from redesigning the system around the patient to co-designing services with the patient. Qual Saf Health Care 2006;15:307-10.

32. McManus V, Abel S, McCreanor T, et al. Narratives of deprivation: women's life stories around Maori sudden infant death syndrome. Soc Sci Med 2010;71:643-9.
33. Williams DR, Collins C. Racial residential segregation: a fundamental cause of racial disparities in health. Public Health Rep 2001;116:404.

34. Walker RC, Howard K, Tong A, et al. The economic considerations of patients and caregivers in choice of dialysis modality. Hemodial Int 2016;20:634-42.

35. Yeates KE, Cass A, Sequist TD, et al. Indigenous people in Australia, Canada, New Zealand and the United States are less likely to receive renal transplantation. Kidney Int 2009;76:659-64.

36. New Zealand National Renal Advisory Board. Standards and Audit report 2012/2013. Wellington, New Zealand: Publisher Ministry of Health, 2014. 